ALTERIDADES, 2018, 28 (55): Págs. 49-60 https:www.doi.org/10.24275/uam/izt/dcsh/alteridades / 2018v28n55/Martinez

\title{
Discriminación y colonialidad en el Ecuador de Rafael Correa $(2007-2017)^{*}$
}

CARMEN MARTÍNEZ NOVO**

\begin{abstract}
Discrimination ANd COlONiAlity in RAFAEl CORREA's ECUADOR (2007-2017). Two forms of discrimination against indigenous people in Ecuador are examined: ventriloquism, when non-indigenous people speak on behalf of indigenous people; and public racism, when State authorities use repression based on the humiliations practiced in their colonial past. The example of ventriloquism discussed is the concept of good living, or Sumak Kawsay, during Rafael Correa's government. The examples of public racism are taken from the repressive practices of the security forces of the regime. This article also reflects on the role of some decolonial scholars in informing and promoting the policies of the government of Rafael Correa towards indigenous peoples and the environment. It is argued that while these academics have called the regime decolonial, its ventriloquist and repressive practices are based on a repertoire with deep colonial roots.
\end{abstract}

Key words: ventriloquism, racism, colonialism, decolonial turn, Andes, indigenous people

\section{Resumen}

Se examinan dos formas de discriminación contra los indígenas en Ecuador: la ventriloquía, cuando los no indígenas hablan por los indígenas, y el racismo público, cuando las autoridades del Estado usan formas de represión basadas en humillaciones típicas del pasado colonial o de la hacienda. El ejemplo de ventriloquía discutido es el concepto de buen vivir o sumak kawsay en el gobierno del presidente Rafael Correa. Los ejemplos de racismo público se toman de las prácticas represivas de las fuerzas de seguridad del régimen. Se ofrece una reflexión sobre el papel que han jugado algunos académicos de la llamada inflexión decolonial en asesorar y promover las políticas del régimen de Correa hacia los pueblos indígenas y el medio ambiente. Se sostiene que mientras estos académicos han llamado al régimen de Correa decolonial, las prácticas ventrílocuas y represivas de éste se han basado en un repertorio de acciones de fuerte raigambre colonial.

Palabras clave: ventriloquía, racismo, colonialismo, inflexión decolonial, Andes, indígenas

\section{Introducción}

$\mathrm{E}$ ste artículo revisa dos maneras de discriminación contra los indígenas en Ecuador: por un lado, la ventriloquía, cuando los no indígenas hablan por los indígenas; por el otro, el racismo público, cuando el Estado los reprime y humilla. El ejemplo de ventriloquía que se discute es el concepto de buen vivir (sumak kawsay

\footnotetext{
* Artículo recibido el 07/08/17 y aceptado el 31/10/17. Este artículo se escribió durante un permiso de investigación financiado por el American Council of Learned Societies y por la Universidad de Kentucky. Agradezco a los dos lectores anónimos de la revista Alteridades por sus comentarios.

** Departamento de Antropología, Universidad de Kentucky. 203 C Lafferty Hall, Lexington, KY, 40506, Estados Unidos <carmen.martinez@uky.edu>.orcID: https://orcid.org/0000-0002-8775-0044
} 
en idioma kichwa) en el gobierno del presidente Rafael Correa (2007-2017). Los ejemplos de racismo público se toman de las prácticas represivas de las fuerzas de seguridad del mismo régimen. ${ }^{1}$

El sumak kawsay se entiende como una forma de vivir apropiadamente desde el punto de vista de la cosmovisión andina o indígena. Este trabajo plantea que el concepto no se origina en el pasado o presente de las comunidades, sino en la intersección entre el mundo del desarrollo, los intelectuales indígenas, el ecologismo y la política populista. Además examina diversos proyectos que se cobijan bajo el sumak kawsay y analiza el concepto como una forma de ventriloquía, una práctica que, se argumentará, se remonta al pasado colonial. Asimismo sostiene que cuando el gobierno de Correa reprime a líderes y organizaciones los castigos no son arbitrarios, sino que se asemejan a humillaciones típicas del pasado colonial y de la hacienda.

Este artículo también es una reflexión sobre el papel que han jugado algunos académicos de la inflexión decolonial (Restrepo y Rojas, 2010) en asesorar y promover las políticas del régimen de Rafael Correa hacia los pueblos indígenas y el medio ambiente. A los teóricos decoloniales les fascinaron las oportunidades que se abrieron cuando subió al poder una serie de gobiernos autodenominados de izquierda en América Latina en la primera década del siglo xxI (Mignolo, 2006; De la Cadena, 2010; Escobar, 2010; Walsh, 2009). Estos autores explicaron el giro político como resultado de las luchas de los movimientos indígenas $\mathrm{y}$ afrodescendientes y señalaron que las epistemologías de esos grupos fueron capaces de emerger en la política convencional latinoamericana. Algunos de estos investigadores se animaron a operar como consejeros formales o informales de esos regímenes, sobre todo al principio y en los momentos constituyentes. Estos académicos han caracterizado al régimen de Correa como decolonial, cuando este gobierno ha usado un vocabulario y repertorio coloniales. Quizás lo colonial se ha confundido con lo decolonial porque conceptos ventrílocuos como el buen vivir han sido tomados por puntos de vista genuinamente indígenas. Además, algunos académicos han aceptado los estereotipos ventrílocuos como cosmovisiones indígenas genuinas debido a su falta de interés por averiguar si estas ideas tienen una base empírica ya sea etnohistórica o etnográfica. Por último, este ensayo sostiene que los teóricos decoloniales, cuando toman distancia de estos gobiernos porque se han vuelto más autoritarios y han priorizado la extracción de recursos naturales sobre los derechos indígenas, han sido insuficientemente autocríticos en cuanto a su complicidad con el proyecto represivo del Estado respecto a las comunidades indígenas.

Este trabajo utiliza la idea de estudiar hacia arriba (Nader, 1972) según la cual el investigador debe enfocarse en estudiar al Estado y a los grupos de poder para comprender su relación con los sectores subalternos. Estudiar hacia arriba permite entender cómo se ejerce el poder a través del control de las instituciones y de la posibilidad de conformar actitudes. Esta metodología también es una forma de humanizar al Estado y de desentrañar cómo funciona detrás de bastidores. Sin embargo, estudiar hacia arriba presenta dificultades, pues los poderosos se resisten a ser observados y es difícil tener acceso a ellos.

La discusión que se expone a continuación está basada en el análisis de textos y la observación participante de la autora con funcionarios y grupos de poder, así como en trabajo en las comunidades y con los intelectuales indígenas. Aunque es difícil acceder a los grupos de poder, la autora laboró por ocho años en la Facultad Latinoamericana de Ciencias Sociales, Ecuador, de donde procedieron cuadros altos y medios del gobierno de Correa.

El artículo explora los múltiples contextos de los discursos y las prácticas para comprenderlos mejor a través de lo que se ha llamado contextualismo radical (Grossberg, 2006). Se interpretan los textos y las prácticas localizándolos en su historia política y en sus múltiples contextos. Esta metodología también se nutre de la tradición antropológica de economía política que requiere que los antropólogos no entiendan a sus sujetos de estudio como si estuvieran aislados, sino como parte de procesos históricos y geográficos más amplios (Wolf, 1982; Mintz, 1985). Finalmente, el contextualismo radical tiene la vocación de entender una coyuntura política para actuar sobre ella con mayor efectividad.

\section{La inflexión decolonial y el gobierno de Rafael Correa}

Los autores decoloniales se interesaron por el llamado giro a la izquierda en América Latina porque pensaron que este cambio político combinaba tendencias

\footnotetext{
${ }^{1}$ Aunque es un tema relevante, este artículo no se centrará en el racismo contra los afroecuatorianos ni en las luchas de este grupo contra la discriminación. Para una introducción a las luchas del pueblo afroecuatoriano y a su relación con el gobierno de Rafael Correa, véanse Rahier (2012), De la Torre y Antón Sánchez (2012), y Martínez Novo (2015).
} 
anticapitalistas o antineoliberales con las cosmovisiones de los movimientos indígenas y afrodescendientes. Arturo Escobar (2010) fue uno de los primeros en examinar las posibilidades del giro político en Venezuela, Bolivia y Ecuador. Se preguntó si estos regímenes buscaban formas alternativas de modernización, antineoliberales pero aún centradas en valores eurocéntricos, o abrían nuevas posibilidades para la activación política de las ontologías relacionales. Considera que las ontologías relacionales rechazan la dicotomía eurocéntrica entre la naturaleza y la cultura y se enfocan en los valores comunitarios en lugar de los valores liberales del individuo, la propiedad privada y el Estado. Le impresionaron particularmente las declaraciones estatales de plurinacionalidad e interculturalidad, las prácticas de democracia directa y el desarrollo endógeno con base en el concepto del buen vivir. Según él, el sumak kawsay empujó a Ecuador a tomar un giro biocéntrico: por primera vez la naturaleza se convirtió en sujeto de derechos. Asimismo sostuvo, aunque algo ambiguamente, que los cambios políticos que atestiguaba no eran tan sólo un giro a la izquierda sino también un giro decolonial.

Marisol de la Cadena (2010) estuvo de acuerdo con Escobar en que entender la naturaleza como sujeto de derechos en la constitución ecuatoriana de 2008 era resultado de la emergencia de las ontologías andinas en la política convencional latinoamericana. En

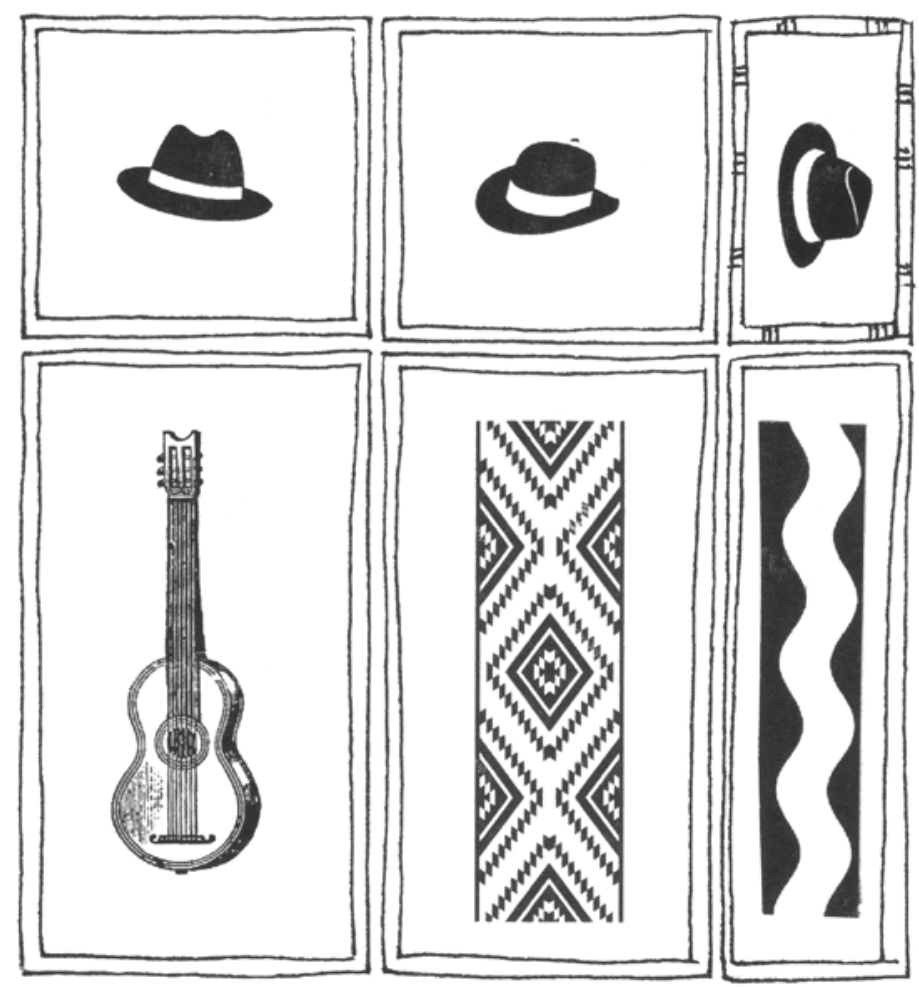

función de su investigación con líderes espirituales del Cusco, De la Cadena planteó que los pueblos indígenas ven a instancias naturales como las montañas -lo que llama seres de la tierra (earth beings)- como capaces de subjetividad y acción política. Para ella, la constitución ecuatoriana de 2008 implementó estos puntos de vista en las políticas públicas latinoamericanas. La autora, sin embargo, asumió que la cosmovisión indígena inspiró la puesta en marcha de estas políticas sin haber investigado el proceso constituyente ecuatoriano y cómo los derechos de la naturaleza llegaron a la constitución de 2008.

Catherine Walsh (2009) también elogió los logros decoloniales de los regímenes de Rafael Correa y Evo Morales (2005-presente) en su libro Interculturalidad, Estado y sociedad. Señala que estos regímenes abandonaron el modelo neoliberal y permitieron que las diferencias étnicas guiaran el debate. Para ella, la innovación más importante fue la interculturalidad, la cual entiende como un proyecto decolonial que se origina en el pensamiento indígena y afrodescendiente y que busca la creación de una nueva sociedad basada en las interacciones armoniosas, la complementariedad y una nueva relación con la naturaleza.

Cuando el gobierno de Correa y otros asociados con el giro a la izquierda en América Latina se volvieron más autoritarios, más centrados en la extracción de recursos naturales y más represivos de los movimientos sociales, aumentó el escepticismo entre los académicos de la inflexión decolonial. Sin embargo, muchas de sus publicaciones han permanecido ambiguas y no han desarrollado una crítica sustantiva de su propio papel en el diseño y promoción de estos proyectos políticos. Por ejemplo, en una publicación que se enfoca en la crisis de la izquierda en América Latina, Escobar (2016) insiste en que el pensamiento crítico no ha decaído en la región, sino que continúa siendo fuerte en las propuestas de los movimientos sociales. Reconoce de pasada el agotamiento del modelo estatal neoextractivista, pero prefiere evitar esta discusión centrándose preferentemente en las ideas que emergen desde abajo. En un artículo reciente sobre acción afirmativa en América Latina, Walsh (2015) elogia al gobierno ecuatoriano por sus políticas de antidiscriminación y acción afirmativa que ella define como decoloniales. Reconoce que estas leyes no se han implementado a plenitud, pero lo justifica argumentando que el régimen ha priorizado la reducción de la pobreza. Como Escobar, escoge enfocarse en el activismo afroecuatoriano y en el empoderamiento desde abajo como una forma de lo que ella llama accionar afirmativo. Cuando amplía el concepto de acción afirmativa para incluir el activismo cultural, 
en lugar de entender acción afirmativa como políticas públicas que buscan remediar las injusticias pasadas, Walsh introduce confusión y trivializa el término.

A pesar de la creciente evidencia del asalto del gobierno de Correa a los movimientos sociales y al medio ambiente, que se detallará más adelante, las críticas decoloniales permanecen ambiguas y tímidas. Estos autores evitan criticar a gobiernos que aún son etiquetados como de izquierda o parecen temer las consecuencias de una posición crítica.

\section{¿Decolonialidad o ventriloquía? Analizando formas sutiles de discriminación}

Aunque estos y otros académicos han interpretado las políticas del gobierno de Correa y en particular el concepto del buen vivir como potencialmente descolonizadores, ${ }^{2}$ sitúo el sumak kawsay dentro de la tradición colonial de que los no indígenas hablen por los indígenas.

Andrés Guerrero (2010) ha denominado a esta práctica ventriloquía, es decir, que los no indígenas hablen por los indígenas, especialmente en las cortes de justicia y frente al Estado. Esta práctica tuvo su origen durante el periodo colonial cuando la población se dividió entre las repúblicas de españoles y las de indios. Se separó a los indios de los españoles con el propósito de cobrar tributo a los primeros. Para evitar abusos en su cobro y para proteger a las poblaciones diezmadas por la conquista, los monarcas peninsulares establecieron la figura de los "protectores de indios". La función de protección se justificaba por el estatuto legal de "miserable" de los indios. Esta categoría, con origen en debates teológicos del siglo xvI, se recogió en las cédulas reales y en la recopilación de las Leyes de Indias.

Con la independencia de la Gran Colombia en 1821 , se trató de suprimir el tributo, pero la figura fue restaurada por Simón Bolívar en 1828 con la denominación de "contribución personal de indígenas". Teóricamente, los indígenas se convirtieron en ciudadanos, pero en la práctica se les excluyó de la ciudadanía. Para votar y ser elegido se requería tener propiedad, no trabajar para otros (no tener una relación de dependencia), poseer la calidad de "vecino" y estar alfabetizado en español, condiciones que los indígenas no cumplían. Hay que señalar que el término "vecino" distinguía a aquellos que eran percibidos como descendientes de españoles. Además, se mantuvo la categoría legal de miserables para los indios. El estatuto de miseria se justificaba por "una historia de opresión, las situaciones sociales de dependencia, el idioma ilegible, la degradación biológica, el estadio de desarrollo cultural y la condición sicológica de los indígenas como adultosniños" (Guerrero, 2010: 240). Este estatus legal definía a los indios como incapacitados para ejercer derechos y los ponía bajo la tutela del Estado. Por esta razón se dictaron procedimientos jurídicos de excepción, y se mantuvo el cuerpo de protectores de indios, cuyo propósito era que las poblaciones en condición de miseria fueran representadas en lo jurídico y lo político.

Al suprimirse el tributo indígena en 1857, la administración de la población indígena se privatizó (Guerrero, 2010): los indígenas ahora eran administrados directamente por las haciendas a las que estaban adscritos así como por los poderes locales de cantones y parroquias. El concepto de protector de indios se suprimió, pero la costumbre subsistió. Escribanos locales, notarios, abogados, y vecinos alfabetizados continuaron escribiendo por los indígenas. Según Guerrero, estos "ventrílocuos" siguieron representando a los comuneros hasta el surgimiento del movimiento indígena en 1990.

La ventriloquía de protectores y escribanos no consistía únicamente en traducir del kichwa oral al español escrito, sino también en redactar las peticiones en un lenguaje jurídico que los funcionarios pudieran comprender y aceptar, y en aconsejar a los indígenas estrategias para tener más posibilidad de ser escuchados.

En un capítulo muy influyente escrito después del levantamiento indígena de 1990 que paralizó el Ecuador e hizo que los mestizos urbanos se dieran cuenta de la existencia del movimiento indígena moderno, Andrés Guerrero (1993) declaró que la ventriloquía había terminado. Observó a los líderes indígenas expresando sus demandas directamente, sin necesidad de intermediarios. Otros académicos después de Guerrero han repetido que la ventriloquía se acabó después de la formación del movimiento indígena moderno, al cual ven como no mediado (Becker, 2012; Lucero, 2008). Este artículo sostiene que el legado de la ventriloquía continúa siendo relevante para las experiencias contemporáneas de los indígenas ecuatorianos. El concepto de ventriloquía explica por qué parece natural para los blanco-mestizos escuchar a no indígenas hablando por los indígenas y aceptar estas manifestaciones como puntos de vista indígenas.

2 Otros autores han sido críticos del concepto y han indicado que no procede del mundo indígena sino que es una tradición inventada. Véanse Bretón (2014, 2017), Viola (2014), Domínguez, Caria y León (2017). 
Empero, el concepto de Guerrero no enfatiza suficientemente las relaciones de poder que impregnan las prácticas ventrílocuas, en particular la deformación de las ideas que se atribuyen a los indígenas, el silenciamiento de las voces y agendas indígenas, y la intensificación de las desigualdades entre los que representan y aquellos que son representados. Además, la representación ventrílocua es una forma de humillación, una herida racista.

Con base en su estudio sobre mestizos que representan a chamanes indígenas en el estado de Chiapas, Pedro Pitarch (2007) añade que la ventriloquía es también un estilo discursivo. Presta atención a cómo se logra el efecto ventrílocuo a través de temas y recursos estilísticos que hacen que el discurso parezca originarse en el grupo indígena desde el punto de vista de los mestizos. Según Pitarch, el efecto ventrílocuo se consigue mezclando algunas palabras en idioma indígena con un discurso en castellano. Otra estrategia común es mezclar retórica new age con discursos de izquierdas y ecologista.

Pitarch (2004) también estudia la ventriloquía del subcomandante Marcos. El autor argumenta que el Ejército Zapatista era en origen una guerrilla marxista. Sin embargo, en entrevistas y columnas de opinión del diario La Jornada la rebelión comenzó a representarse como un movimiento indígena. Viendo que la política de la identidad atraía simpatía en México y en el nivel internacional, el subcomandante Marcos aceptó esta representación. Para hacerla más creíble, el subcomandante adoptó un "lenguaje indio" aunque no hablaba una lengua originaria. Empezó a hablar como la población mestiza imagina que hablan los indios: una mezcla de expresiones en español chiapaneco arcaico, la gramática de los indios en las películas del oeste, y motivos románticos y pastorales (Pitarch, 2004: 298). El investigador plantea que el efecto ventrílocuo otorgó gran capital simbólico a los zapatistas por varias razones: los indígenas simbolizan los márgenes y la esencia de la nación, y el discurso nacionalista desde los márgenes tiene gran poder; además, el discurso ventrílocuo era simple y repleto de lugares comunes que podían ser interpretados como llenos de sabiduría - la cual se atribuía a las culturas ancestrales- y apropiados a voluntad. Por otra parte, hubo una falta de interés por averiguar si el discurso de Marcos realmente provenía del mundo indígena. Los que conocían bien el mundo indígena de Chiapas, por ejemplo antropólogos que llevaban allí muchos años, mantuvieron la ficción para apoyar a los indígenas en sus luchas, porque fueron seducidos por el romanticismo de los líderes zapatistas, y porque criticar a los zapatistas tenía un costo y promo- verlos traía ventajas profesionales. Pitarch (2007) ve la ventriloquía como un fenómeno específicamente mexicano, pues sostiene que el Estado ha representado a la población indígena a través de grupos corporativos liderados por mestizos desde la Revolución. Sin embargo, el Estado mexicano parece haber replicado prácticas coloniales más antiguas similares a las que observamos en Ecuador.

Aun cuando resulta importante analizar las formas de dominación sutiles como la ventriloquía, este artículo argumenta que también es revelador conectar las prácticas paternalistas con la reemergencia del racismo abierto. ¿Es el racismo abierto una manera de suprimir las voces subalternas que tratan de escapar a los límites de la ventriloquía? ¿O estamos presenciando la transición de un racismo velado a expresiones de racismo más crudas? ¿Qué factores podrían estar detrás de esta transición?

\section{El sumak kawsay en el gobierno de Rafael Correa}

El término buen vivir se encuentra con frecuencia en la constitución ecuatoriana de 2008 así como en los planes nacionales de desarrollo. En la Constitución, el buen vivir aparece más visiblemente en el título II, que se enfoca en la definición de los derechos. El capítulo segundo del título II está dedicado a los "Derechos del Buen Vivir", que incluyen el acceso al agua, comida, un medioambiente sano, cultura, comunicación, educación, vivienda y trabajo. Otra sección de la Constitución que trata del buen vivir es el título VII "Sobre el régimen del Buen Vivir", que discute la igualdad, la educación, la salud, la seguridad social, la vivienda, la cultura, la ciencia, el conocimiento ancestral y la movilidad humana. La Asamblea Constituyente parece haber entendido el buen vivir como un subtipo de derechos de segunda y tercera generación ligados a la idea de democracia sustantiva, o democracia que va más allá de los derechos políticos y civiles (de primera generación) y que incluye los derechos económicos, sociales (de segunda generación), grupales, y medioambientales (de tercera generación). No hay nada que aluda específicamente a la filosofía indígena en los artículos que se encuentran bajo el acápite Buen Vivir, excepto quizás el hecho de que estos derechos incluyen la igualdad y la promoción de la diversidad.

La Secretaría Nacional de Planificación y Desarrollo (Senplades) es la institución que formula los planes de desarrollo y ha sido una de las principales promotoras del concepto del buen vivir en el Ecuador, la 
cual demostró una relación ventrílocua con los pueblos indígenas desde su creación. Cuando la agencia presentó su primer plan de desarrollo 2007-2009, lo hizo en la Capilla del Hombre, un museo diseñado por el muralista indigenista Osvaldo Guayasamin. La autora asistió a esta ceremonia. Cuando los actores del desarrollo, incluyendo las autoridades electas indígenas, llegaron a la Capilla, los recibió una fila de hombres y mujeres mestizos disfrazados de las 14 nacionalidades indígenas del Ecuador. Cada "nacionalidad" llevaba una pancarta que explicaba un objetivo de desarrollo tal como lo había concebido la Senplades. En la ceremonia los funcionarios ofrecieron una presentación en Power Point al público. No hubo tiempo para el diálogo. Sin embargo, sí hubo oportunidad de disfrutar de bailes folclóricos interpretados por mestizos disfrazados de indígenas.

Los bailes y la representación de las nacionalidades corrieron a cargo del ballet folclórico Jacchigua, uno de los favoritos del presidente Rafael Correa, quien le otorgó al grupo en 2010 el prestigioso premio nacional Eugenio Espejo. Según la página web del ballet, éste fue creado a principios de los años noventa por la compañía Metropolitan Touring, propiedad de una de las familias más aristocráticas de Quito. Rafael Camino, fundador del ballet, informa que:

El nombre del grupo proviene de la palabra Jacchima que expresa la fiesta que el patrón daba el último viernes de Junio o el primer viernes de Julio por la cosecha en el patio de la hacienda. Allí los huasicamas [los que servían en la casa del patrón] y los husipungueros [los trabajadores de la hacienda] disfrutaban de un día de fiesta con el patrón y su familia. ${ }^{3}$

En el régimen de Correa existió un patrón de que mestizos representaran a indígenas. Por ejemplo, cuando el gobierno, en colaboración con la Conferencia Episcopal, organizó el viaje del papa Francisco a Ecuador en julio de 2015, el régimen presentó la diversidad cultural del país al pontífice a través de mestizos vestidos con indumentaria indígena. No se permitió a la Confederación de Nacionalidades Indígenas del Ecuador (Conaie) tener una audiencia con el papa. Los disfrazados fueron denunciados en las redes sociales como impostores por las comunidades a las que representaban.

El Plan Nacional del Buen Vivir 2009-2013, diseñado bajo el liderazgo de René Ramírez, economista y segundo de a bordo del gobierno de Correa, promovió una visión ecléctica del sumak kawsay. El plan afirmaba vagamente los orígenes indígenas del concepto, pero lo que en realidad lo inspiró fueron las teorías del premio Nobel Amartya Sen y de autores ecologistas y posdesarrollistas. Siguiendo a Sen, el plan definió el buen vivir como el incremento de las capacidades y oportunidades humanas.

Ramírez no fue el primero dentro del círculo político de Correa en proponer la idea del buen vivir. Se considera al político kichwa Carlos Viteri como el primero que usó el término sumak kawsay en Ecuador. Viteri estudió en la Universidad Politécnica Salesiana, trabajó para el Banco Interamericano de Desarrollo, desde 2009 es miembro de Alianza País, el partido de gobierno, y como tal ha sido elegido a varios cargos de representación. Actualmente es representante de Alianza País en la Asamblea Nacional. El sumak kawsay, según Viteri (2002), enfatiza la solidaridad, la reciprocidad, la minga ${ }^{4}$ y el manejo correcto de la biodiversidad. En su página web de la Asamblea Nacional, Viteri afirma que: "propuso en 1993 el Sumak Kawsay (vivir en abundancia, sabiduría y dignidad) como un nuevo paradigma para alcanzar el buen vivir en armonía entre los pueblos y culturas y en equilibrio con la madre naturaleza frente al fracaso mundial de la ideología del desarrollo". ${ }^{5}$

El economista medioambiental y expresidente de la Asamblea Constituyente Alberto Acosta dice haber tomado el término sumak kawsay de un editorial de Viteri. A Acosta le gustó el término y decidió incorporarlo al texto constitucional aprobado en 2008. Acosta y la medioambientalista Esperanza Martínez (2009) definen sumak kawsay como un concepto que implica varios proyectos utópicos que se relacionan difusamente con lo indígena. Éstos incluyen el rechazo del extractivismo, la idea de la ciudadanía universal, y las estrategias económicas cooperativas basadas en la solidaridad y reciprocidad.

Eduardo Gudynas y Catherine Walsh, que asesoraron a Acosta en la Asamblea Constituyente 20072008, también resaltan la importancia del sumak kawsay y lo definen de la siguiente manera: Walsh (2009) cita profusamente del libro Filosofía andina, del teólogo suizo Josef Estermann (1998), para delimitar el concepto, aunque el buen vivir como tal no aparece en ese texto. Para Walsh, el sumak kawsay es central para implementar la interculturalidad. Cuando los colonizadores llegaron a América, prohibieron

\footnotetext{
3 http:www.jacchiguaesecuador.com [octubre de 2016].

4 Trabajo colectivo, similar al tequio.

5 www.asambleanacional.gob.ec/es/contenido/perfildecarlosviteri [ $1^{\circ}$ de agosto de 2017].
} 
a los indígenas adorar la naturaleza, actividad que se consideró como idolatría. Por eso, argumenta Walsh, cambiar nuestra relación con la naturaleza es un acto decolonial. La autora alaba el sumak kawsay porque este concepto no se reduce al desarrollo económico, sino que incluye lo espiritual y lo epistémico.

Gudynas (2011) comparte con los autores antes mencionados una noción vaga del buen vivir como una plataforma para varias visiones críticas al desarrollo. El buen vivir se sitúa, según Gudynas, más allá de nociones tradicionales de desarrollo e incluye valores culturales, espirituales y estéticos. La naturaleza se convierte en sujeto y los seres humanos no son la única fuente de valores. Gudynas reconoce que el concepto se basa en una mezcla de puntos de vista indígenas, la reacción contemporánea de los pueblos indígenas al desarrollo, y las ideas decoloniales de intelectuales como Arturo Escobar y Walter Mignolo.

Otra dependencia gubernamental que promovió el buen vivir fue la secretaría del mismo nombre liderada por Freddy Ehlers, periodista y productor de televisión. Fue creada por iniciativa del presidente Correa en junio de 2013, tenía rango de ministerio, alrededor de 30 funcionarios, y un presupuesto de 12 millones de dólares para cuatro años (Neira, 2015). La institución entendía el buen vivir como "un modelo sostenible de vida armoniosa que posibilite las condiciones para que se maximice la felicidad de todos" (Secretaría del Buen Vivir, 2015: 3), y señalaba que este concepto era una creación de pueblos ancestrales como los kichwas, aymaras, guaraníes, tzeltales, kunas y miskitos. Frente a la crisis civilizatoria y el cambio climático, veía el buen vivir como una ideología de armonía con la naturaleza que se reflejaba en la consagración de los derechos de la naturaleza en la constitución ecuatoriana de 2008. Una publicación de la dependencia conectaba el buen vivir con el debate sobre la felicidad (Secretaría del Buen Vivir, 2015), el cual surge de un grupo de economistas, algunos de ellos de la Comisión Económica para América Latina y el Caribe (CEPAL), que desde los años setenta postularon que no hay correlación entre desarrollo y felicidad. Las fuentes de la Secretaría eran eclécticas. Además de citar a la CEPAL, usó conceptos de psicología positiva tomados de cursos en línea de Harvard y Berkeley. Otra fuente de inspiración fue el rey de Bután, que lleva 40 años argumentando que la felicidad es más importante que el desarrollo.

En otra sección de la publicación se comunicaba qué hacía la Secretaría en concreto: realizaba progra- mas de televisión sobre la naturaleza y la felicidad. También daba talleres en varios países para dar a conocer el concepto. Además estaba interesada en fomentar un modelo de vida consciente que incluyera la meditación zen y la alimentación orgánica. Cabe anotar que el ministro Ehlers era un entusiasta budista. La dependencia contó entre sus logros que más personas conocieran el buen vivir a través de programas de televisión. Asimismo impulsó la creación de indicadores de buen vivir en una reunión de métricas de la felicidad en Bután. Finalmente promovió la meditación zen en los colegios ecuatorianos, así como descansos lúdico-deportivos para los burócratas (Constante, 2014).

La Secretaría fue blanco de múltiples chistes que denominaron a los allegados a Correa como "El círculo del Buen Vivir", refiriéndose a la corrupción de la que se les acusaba (Neira, 2015). Algunos cambiaron su nombre por "Secretaría del Buen Beber". Además ha existido molestia con el uso de fondos públicos para la propaganda en un país con numerosas necesidades insatisfechas (Neira, 2015). El gobierno del presidente Lenín Moreno (2017-presente) eliminó la Secretaría mediante el decreto del 3 de mayo de 2017 en un esfuerzo por cortar presupuestos y acabar con la corrupción (Radio Huancavilca, 2017).

Hay dos formas diferentes y complementarias de entender el buen vivir en el gobierno de Correa: por un lado, el sumak kawsay es una plataforma para una serie de proyectos ecologistas, antineoliberales y posdesarrollistas con influencia de autores decoloniales e incluso de los del giro ontológico; ${ }^{6}$ por el otro, es una versión new age de lo indígena con énfasis en la espiritualidad, la comunidad, y la armonía con la naturaleza. Lo indígena provee coherencia, un término atrayente y poder simbólico a un conjunto ecléctico de proyectos. Autores como Walsh y Gudynas contribuyeron a definir, institucionalizar y promover este concepto tanto durante su participación en la Asamblea Constituyente como en sus publicaciones posteriores. Domínguez, Caria y León (2017) y Bretón (2017) señalan que existen tres corrientes de interpretación del sumak kawsay: la del gobierno, la del movimiento indígena y la de los ecologistas. Sin embargo, como muestro en la discusión anterior, ecologistas e intelectuales indígenas participaron en el gobierno de Correa que tomó estas ideas y las utilizó. Creo que las tres corrientes no pueden separarse, y mucho menos caracterizar a dos de ellas como independientes del gobierno cuando lo inspiraron.

6 Aquellos autores que relativizan la separación occidental entre naturaleza y cultura y que sostienen que las ocurrencias naturales poseen subjetividad y agencia. 


\section{El sumak kawsay como discurso ventrílocuo}

Después de estudiar en detalle su genealogía y usos, no sorprende que el sumak kawsay o buen vivir no aparezca en los registros etnohistóricos o etnográficos. De acuerdo con Bretón (2014), sumak kawsay y suma qamaña no aparecen excepto como palabras sueltas en los diccionarios antiguos del quechua y del aymara, en las crónicas coloniales, o en libros académicos sobre la cultura o filosofía andina anteriores al 2000. León Zamosc (2013) sitúa los orígenes del sumak kawsay en Ecuador a principios de los años noventa. La Organización de los Pueblos Indígenas de Pastaza (OPIP), tras una marcha a Quito, logró el reconocimiento de un extenso territorio. Zamosc sugiere que los Viteri, una familia kichwa de la que es miembro el asambleísta Carlos, crearon el concepto de sumak kawsay para negociar fondos con las organizaciones no gubernamentales europeas. Según el autor, el concepto original que la OPIP manejó a principios de los noventa se fundaba en ideas de desarrollo convencionales.

En su tesis de maestría, Guillermo Churuchumbi (2014) investiga el significado del sumak kawsay para los líderes comunitarios de base y para los comuneros de su Cayambe natal. Apunta que estos últimos no usan el término ya que ni siquiera es correcto kichwa. Alli kawsay sería más apropiado. Sin embargo, tampoco utilizan esta denominación a diario. En todo caso, los líderes comunitarios han decidido ofrecer talleres para entrenar a las comunidades en el uso del término debido a su potencial político. Churuchumbi preguntó a los líderes cómo se compara alli kawsay con los conceptos occidentales de desarrollo y progreso. A diferencia de los intelectuales indigenistas, los comuneros entendieron que sumak kawsay, desarrollo y progreso son sinónimos. La interpretación de que alli kawsay es una ideología de armonía con la naturaleza que se opone a la visión occidental de desarrollo y a la modernidad es un discurso ventrílocuo.

\section{La reemergencia del racismo abierto}

Mientras que la administración de Correa se apropiaba del sumak kawsay y aseguraba estar trabajando por la interculturalidad y la plurinacionalidad, contra la discriminación y por los derechos de la naturaleza, el conflicto entre el gobierno y la Conaie empeoraba. $\mathrm{El}$ gobierno ha reducido drásticamente los derechos indígenas desde 2009. Por ejemplo, la autonomía del sistema de educación intercultural bilingüe se suspendió en ese año, después de que el movimiento indígena se manifestara contra una nueva ley de minería que abría la puerta a la minería a gran escala en Ecuador. Se han cerrado alrededor de 13000 escuelas comunitarias y sus estudiantes se han relocalizado en las llamadas escuelas del milenio, que quedan lejos de las comunidades y donde no se imparten la lengua y cultura indígenas. Esto está causando un éxodo desde las comunidades hacia las ciudades medianas y grandes que está liberando tierras para las compañías mineras, madereras y petroleras (Martínez Novo, 2016). El presupuesto del Consejo de Desarrollo de las Nacionalidades y Pueblos del Ecuador también disminuyó dramáticamente en 2009, argumentando que ese dinero se había empleado en manifestaciones antimineras. Más tarde se cerró la institución indígena de desarrollo y se sustituyó por un Consejo de la Igualdad, cuyos miembros no son elegidos por las organizaciones indígenas sino por un organismo cercano al ejecutivo (Martínez Novo, 2016). El pluralismo jurídico que se reconoció en las constituciones de 1998 y 2008 se ha circunscrito a través de una sentencia del tribunal constitucional de 2014 a asuntos internos entre indígenas que afecten a la cultura o la identidad. $^{7}$

Cuando las organizaciones indígenas han protestado por estos y otros atropellos, han sido duramente reprimidas. El gobierno de Rafael Correa usó los delitos de sabotaje, terrorismo y resistencia, vagamente definidos en el nuevo código penal, para criminalizar la protesta. La represión a través del sistema legal se complementó con el Decreto Ejecutivo 16 que permitió al gobierno cerrar las organizaciones de la sociedad civil que participaran en política o atentaran contra la "seguridad nacional” (Conaghan, 2015). Más de 700 líderes han sido enjuiciados, la mayoría de ellos activistas que tratan de proteger su territorio del extractivismo. ${ }^{8}$

Aunque las principales organizaciones indígenas se opusieron al régimen de Rafael Correa, algunos cuadros y bases fueron cooptados por el gobierno, y una forma de hacerlo fue mediante el empleo público. Durante una época de boom petrolero, el Estado fue el mayor empleador, y algunos indígenas fueron contratados como gestores de la interculturalidad. En

\footnotetext{
7 Sentencia de la Corte Constitucional n. 113-14-SEP-CC, caso n. 0731-10-EP, 30 de julio de 2014.

8 El Decreto 16 fue derogado en octubre de 2017 por el presidente Lenín Moreno, quien quiere facilitar el trabajo de las asociaciones civiles. Además, Moreno ha indultado o rebajado las penas a líderes indígenas criminalizados.
} 
ocasiones, el gobierno utilizó a estos funcionarios para desmantelar las políticas de desarrollo indígena. Por ejemplo, usó consultores indígenas para justificar el cierre de la Universidad Intercultural de las Nacionalidades y Pueblos Indígenas y de los institutos pedagógicos donde se formaban los maestros bilingües. Los indígenas de base se acercaron al proyecto de Correa a través de las obras, pues se construyeron centros de salud, escuelas del milenio, e incluso complejos de vivienda, sobre todo en las áreas petroleras y mineras.

La represión de las protestas indígenas y de trabajadores en agosto de 2015 fue particularmente severa. En Quito, las fuerzas de seguridad golpearon y detuvieron a líderes indígenas nacionales. El gobierno usó el estado de excepción declarado con motivo de la erupción del volcán Cotopaxi para allanar viviendas en las comunidades indígenas de la sierra y de la Amazonía. La policía tiró bombas lacrimógenas dentro de las casas, golpeó y arrestó a personas que no estaban en las protestas, y golpeó a mujeres embarazadas, niños $\mathrm{y}$ ancianos.

El objetivo del régimen no fue sólo reprimir, sino también humillar a los activistas indígenas. Un análisis de los castigos muestra que éstos están basados en humillaciones que ya se empleaban en el periodo de servidumbre indígena. Por ejemplo, una foto del Colectivo de Investigación/Acción Psicosocial (véase foto 1) muestra a un policía arrancando la pachalina (pañuelo) a una mujer indígena. Al político indígena Salvador Quishpe la policía le quitó su sombrero, símbolo de la identidad saraguro. A varias mujeres les arrancaron los anacos (faldas indígenas) y otras prendas. "Arranchar" prendas a los indígenas tiene una larga tradición en los Andes. En la época de servidumbre indígena anterior a la Reforma Agraria de 1964, las autoridades y los comerciantes blanco-mestizos arrancaban prendas a los indígenas para forzarlos a realizar algún trabajo sin remuneración o a pagar una multa (Burgos, 1997).

Otro castigo ritual que han usado las fuerzas del orden ha sido tirar a los indígenas del cabello o de las trenzas. Una mujer arrestada en Saraguro dice: "La policía me arrastró de la jimba (trenza). Me arrastraron, me pegaron, me arrancaron la ropa. Me insultaron y me dijeron que me iban a violar”. Otra mujer señala: "La policía nos agarró por las trenzas. Nos insultaron. Dijeron: 'Indias sucias, ¿qué hacen aquí? Vayan a trabajar con sus maridos'. Luego dijeron, 'arrástralas por el cabello, vamos a violarlas"” (Resistir es mi derecho, 2015). Tirar del cabello es una humillación que la policía ha empleado tradicionalmente con los indígenas en Ecuador. Por ejemplo, en el libro Relaciones interétnicas en Riobamba (Burgos, 1997 [1970]: 252), que fue escrito cuando todavía existía la servidumbre indígena en la hacienda, hay una foto en la que se observa a un policía tirando del cabello a una mujer indígena mientras una pareja elegante camina por la acera. El pie de foto indica: "Campaña de tránsito de peatones en Riobamba. Los blancos son amonestados de buena manera, pero los indios reciben un sablazo en las canillas o se les tira del cabello 'cariñosamente' como muestra la foto".

Foto 1

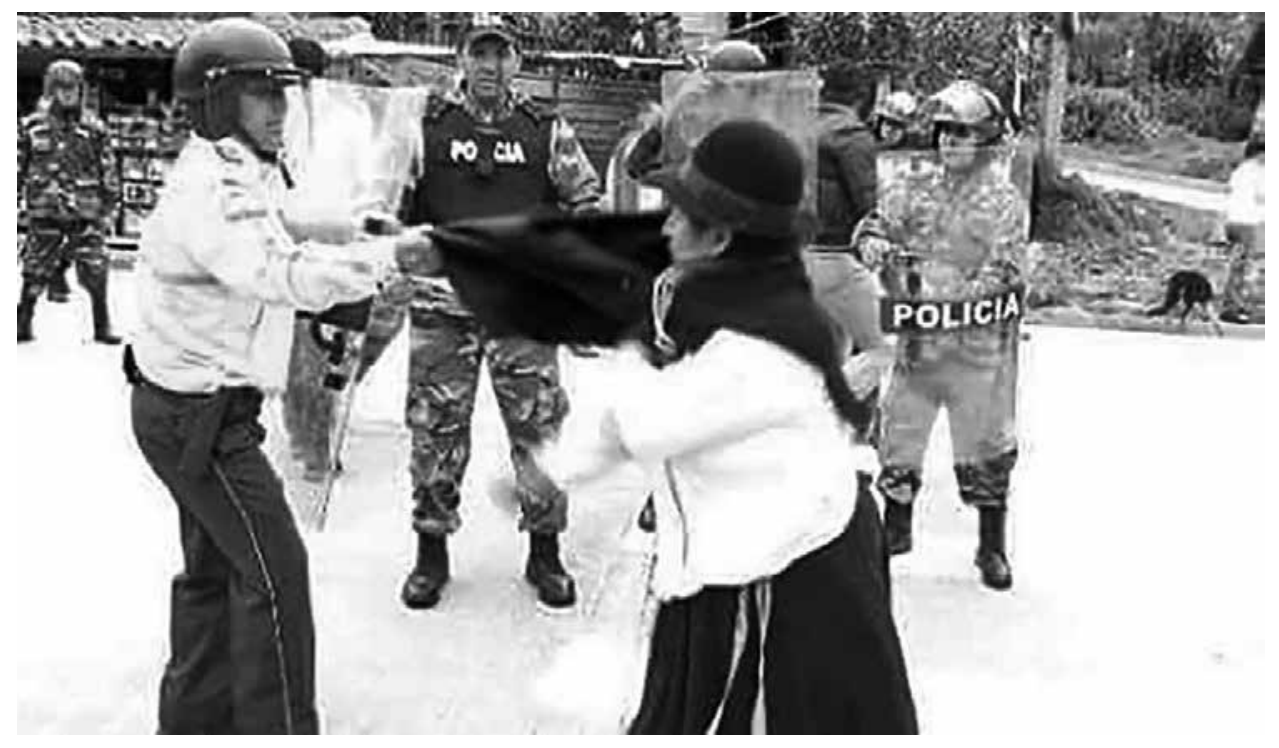

Colectivo de Investigación/Acción Psicosocial (2015) 
Un póster del arresto de Salvador Quishpe apunta:

Salvador Quishpe, líder indígena y gobernador de la provincia de Zamora-Chinchipe, fue humillado ayer por las fuerzas de policía del régimen de Correa en Quito. A Salvador se le arrancó el sombrero, símbolo de su identidad, se le arrastró, golpeó y se le tiznó con una sustancia oscura. El régimen de Correa no duda en herir la dignidad de los líderes populares.

Después de esto, partidarios del régimen distribuyeron un meme a través de las redes sociales donde se usaba una foto de Quishpe durante su detención. Al otro lado se colocó una fotografía de la "mama negra”, el personaje principal de un festival que se celebra en la ciudad de Latacunga desde el siglo xviII. El meme decía "mama negra" debajo del personaje y "mamarracho" debajo de Quishpe (véase figura 1). En el festival de la mama negra, un hombre mestizo se disfraza de mujer negra pintándose la cara. El meme racializaba y feminizaba a Quishpe para humillarlo. El festival de la mama negra tradicionalmente cuenta con dos priostes: el de los blancos y el de los tiznados. Hasta el día de hoy, los seguidores de Correa usan el apodo "carita sucia" para referirse al gobernador Quishpe, cuyo castigo no fue aleatorio. Como se advierte, respondió a un repertorio con profundas raíces coloniales.

\section{Conclusión}

La tradición colonial de la ventriloquía que discute Guerrero (2010) hace que se haga fácil, natural y un hábito para los blanco-mestizos hablar por y representar a los indígenas. Esta tradición también permite que otros no indígenas acepten el discurso ventrílocuo como una expresión indígena genuina si se siguen ciertos patrones estilísticos. Los indígenas, por su parte, se ven presionados a acomodarse a estas representaciones que a su vez tratan de usar estratégicamente.

Si no fuera por el legado de la ventriloquía, hubiera sido difícil para el régimen de Rafael Correa y para sus consejeros apropiarse del sumak kawsay, llenar este significante con diversos proyectos y estereotipos, y proyectarlo a las audiencias nacionales e internacionales e incluso al mundo de las comunidades. La ventriloquía estatal no es muy sofisticada, se basa en estereotipos muy simples y conocidos que no están informados por una interacción prolongada o por una reflexión profunda sobre las culturas y las lenguas indígenas. El éxito del concepto sumak kawsay se
Figura 1

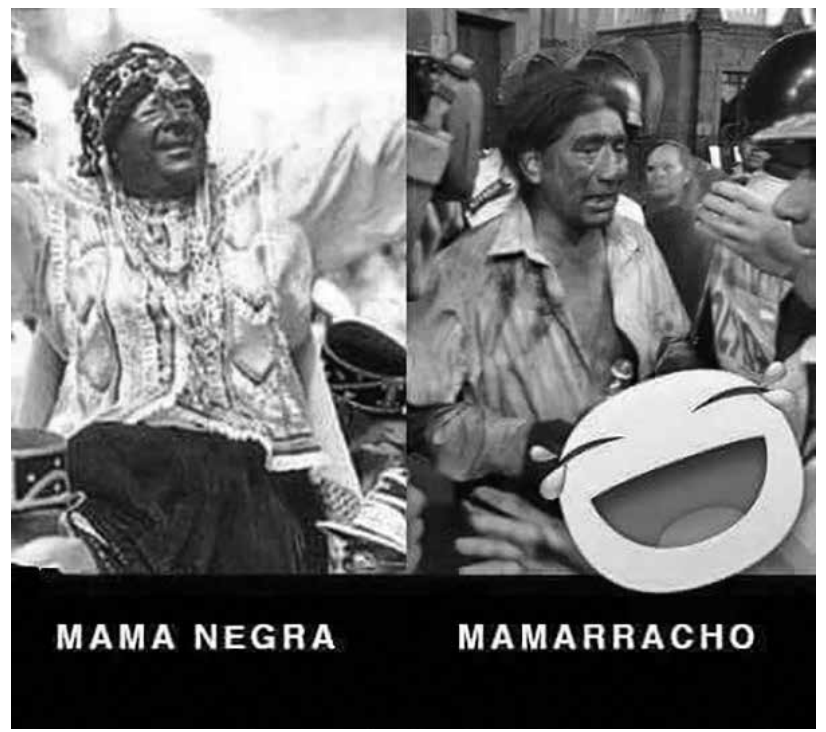

Meme distribuido por partidarios de Correa en las redes sociales, agosto de 2015

explica por razones similares al del discurso "indígena" del subcomandante Marcos (Pitarch, 2004). Se fundamenta en ideas simples y repetitivas con poco significado que cada cual puede apropiarse a su manera. Además, los distintos proyectos que se arropan bajo el acápite sumak kawsay son legitimados por la pureza y el nacionalismo primigenio que emanan de la idea de que el término proviene del mundo indígena. Algunos escritos de los autores de la inflexión decolonial han sido cómplices con esta estrategia y han contribuido a legitimar esta usurpación. Asimismo, el legado de la ventriloquía ha permitido a los autores de la inflexión decolonial definir libremente el sumak kawsay con base en otras fuentes indigenistas sin investigar en el campo o en los archivos cuál es su relación con las comunidades indígenas.

¿Por qué persiste la ventriloquía y cómo se vincula con el racismo abierto? La ventriloquía se origina en un pasado colonial donde se da una administración paternalista. Esta práctica pretende proteger al indio, pero se justifica por su inferioridad, por su condición de miserable. Por lo tanto, la ventriloquía es una forma de racismo, pues no puede existir sin su otra cara, la condición de inferioridad. La ventriloquía duele porque silencia, tergiversa y humilla. Es una herida colonial. Surge la pregunta de si los indígenas pueden ser ventrílocuos de otros indígenas. Esto no es posible, ya que la ventriloquía ha tomado forma históricamente como una relación interétnica fundada en la inferiorización de todo un grupo. Un indígena puede hablar por otros, pero no se trataría de un ventrílocuo en el sentido en que se usa el concepto en este artículo. 
Los autores que escribieron sobre el fin de la ventriloquía pensaron que el empoderamiento indígena era suficiente tras la creación de un movimiento indígena moderno y tras los primeros levantamientos para que esta práctica desapareciera y los indígenas pudieran autorrepresentarse (Guerrero, 1993; Lucero, 2008; Becker, 2012). Sin embargo, estos académicos parecen haber subestimado la persistencia de la discriminación e inferiorización y de la necesidad de los indígenas de acomodarse a la protección paternalista que los silencia. Además, cuando los indígenas tratan de proyectar su propia voz y demandas, son duramente reprimidos. La represión violenta busca reconducirlos a la administración paternalista.

El resurgimiento del racismo abierto, que apenas estuvo contenido durante la época de fuertes movimientos y levantamientos indígenas y del multiculturalismo, toma lugar en circunstancias particulares. Como hemos visto, un contexto importante del recrudecimiento del racismo es el extractivismo. Hale, Calla y Mullings (2017) señalan que estamos siendo testigos de la transición hacia una nueva formación racial donde dejan de expandirse los derechos multiculturales debido a la extracción de recursos naturales, al contraataque de las élites y de los grupos racialmente dominantes ante la expansión de los derechos indígenas, y a la violencia estatal impune contra los pobres no blancos.

Las organizaciones indígenas fueron suficientemente debilitadas por la cooptación neoliberal y por las divisiones creadas por los gobiernos populistas para que las élites y aquellos que se benefician de la decadencia del multiculturalismo puedan escoger una confrontación abierta. Los movimientos sociales fueron fragmentados por la cooptación y por estrategias de discriminación sutil como la ventriloquía. El gobierno de Correa trabajó en dividir a las organizaciones sociales con una mezcla de estrategias clientelares y represivas (véase Martínez Novo, 2014). Las élites toman ventaja de esta debilidad de los movimientos sociales para acceder a una parte mayor de las ganancias que provienen de los recursos naturales. La autonomía, aun superficial, puede amenazar estas ganancias. En este contexto, los grupos dominantes se arriesgan al racismo abierto que se legitima deshumanizando a sus adversarios con humillaciones rituales. Como ocurre con la ventriloquía, el lenguaje de la represión se origina en un repertorio colonial. Tanto cuando se usurpan, tergiversan y silencian las ideas de los indígenas, como cuando se les reprime directamente, el gobierno de Rafael Correa utilizó lo que las élites y los aparatos represivos del Estado conocen mejor, y lo que más hiere: el legado colonial y de la hacienda.

\section{Fuentes}

Acosta, Alberto

y ESPERANZa MarTínez

2009 El buen vivir: una vía para el desarrollo, Abya Yala, Quito.

BECKER, MARC

2012 "The Limits of Indigenismo in Ecuador", en Latin American Perspectives, vol. 39, núm. 5, pp. $45-62$.

BRETÓN, Víctor

2014 "En busca del Sumak Kawsay", en Iconos, núm. 48 , pp. 9-24.

BRETón, Víctor

2017 "Three Divergent Understandings of Buen Vivir in the Ecuador of the Citizen's Revolution", en Latin American and Caribbean Ethnic

Burgos, Hugo Studies, vol. 12, núm. 2, pp. 188-198.

1997 Relaciones interétnicas en Riobamba, Corporación Editora Nacional, Quito [1970].

Cadena, Marisol de la

2010 "Indigenous Cosmopolitics in the Andes: Conceptual Reflections Beyond Politics", en Cultural Anthropology, vol. 25, núm. 2, pp. 334370.

Churuchumbi, Guillermo

2014 "Usos cotidianos del término Sumak Kawsay en el Territorio Kayambi", tesis de maestría Universidad Andina Simón Bolívar, Quito.

Conaghan, Catherine

2015 "Surveil and Sanction: The Reform of the State and Societal Regulation in Ecuador", en European Review of Latin American and Caribbean Studies, núm. 98, pp. 7-27.

Constante, Soraya

2014 "La felicidad es un asunto de Estado", en $\mathrm{El}$ País, Internacional, 21 de octubre.

Domínguez, Rafael, Sara Caria

Y MAURICIO LEÓN

2017 "Buen Vivir: Praise, Instrumentalization, and Reproductive Pathways of Good Living in Ecuador", en Latin American and Caribbean Ethnic Studies, vol. 12, núm. 2, julio, pp. 133-154.

Escobar, Arturo

2010 "Latin America at a Crossroads: Alternative Modernizations, Post-liberalism or Post-development?", en Cultural Studies, vol. 24, núm. 1, pp. 1-65.

Escobar, Arturo

2016 "Desde abajo, por la izquierda y con la tierra", en Eduardo Gudynas (ed.), Rescatar la esperanza: más allá del neoliberalismo y el progresismo, Entrepobles, Barcelona.

Estermann, JoseF

1998 Filosofía andina: sabiduría indígena para un mundo nuevo, Instituto Superior Ecuménico Andino de Teología, La Paz, Bolivia.

Grossberg, LaWrence

2006 "Does Cultural Studies Have Futures? Should it? Or What's the Matter with New York?", en Cultural Studies, vol. 1, núm. 20, pp. 1-32.

Gudynas, EduARDo

2011 "Buen Vivir: Today's Tomorrow", en Development, vol. 54, núm. 4, pp. 441-447.

Guerrero, Andrés

1993 "La desintegración de la administración étnica en el Ecuador", en José Almeida (ed.), Sismo étnico en el Ecuador, Centro de Desarrollo e 


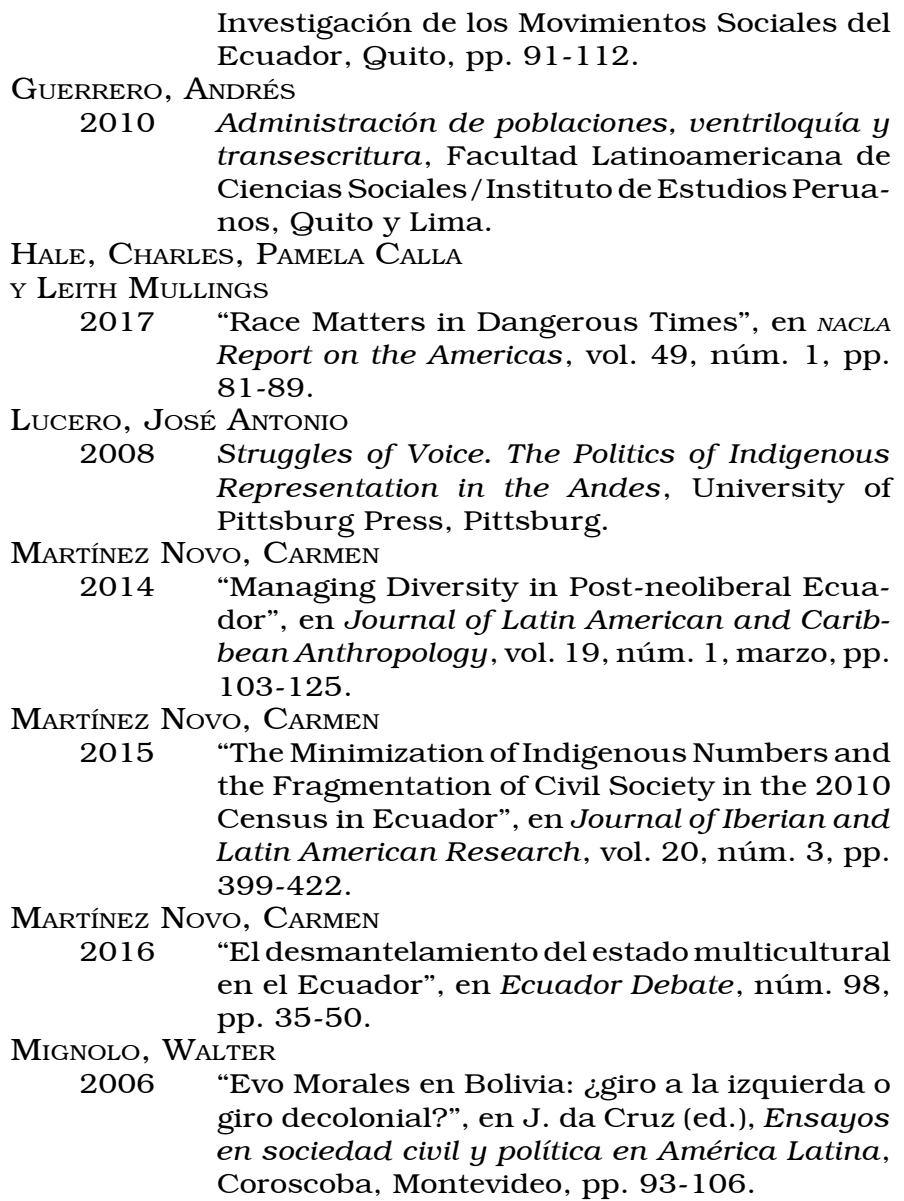

Investigación de los Movimientos Sociales del Ecuador, Quito, pp. 91-112.

Guerrero, Andrés

2010 Administración de poblaciones, ventriloquía y transescritura, Facultad Latinoamericana de Ciencias Sociales / Instituto de Estudios Peruanos, Quito y Lima.

Hale, Charles, Pamela Calla

y Leith Mullings

2017 "Race Matters in Dangerous Times", en NACLA Report on the Americas, vol. 49, núm. 1, pp. 81-89.

Lucero, José AnTONIO

2008 Struggles of Voice. The Politics of Indigenous Representation in the Andes, University of Pittsburg Press, Pittsburg.

Martínez Novo, Carmen

2014 "Managing Diversity in Post-neoliberal Ecuador", en Journal of Latin American and Caribbean Anthropology, vol. 19, núm. 1, marzo, pp. 103-125.

Martínez Novo, Carmen

2015 "The Minimization of Indigenous Numbers and the Fragmentation of Civil Society in the 2010 Census in Ecuador", en Journal of Iberian and Latin American Research, vol. 20, núm. 3, pp. 399-422.

Martínez Novo, CARMen

2016 "El desmantelamiento del estado multicultural en el Ecuador", en Ecuador Debate, núm. 98, pp. 35-50.

Mignolo, WaLter

2006 "Evo Morales en Bolivia: ¿giro a la izquierda o giro decolonial?", en J. da Cruz (ed.), Ensayos en sociedad civil y política en América Latina, Coroscoba, Montevideo, pp. 93-106.

MinTZ, Sidney

1985 Sweetness and Power: The Place of Sugar in Modern History, Penguin, Nueva York.

NADER, LAURA

1972 "Up the Anthropologist: Perspectives Gained by Studying Up”, en Dell Hymes (ed.), Reinventing Anthropology, Pantheon, Nueva York, pp.

NeIra, Mariana 284-311.

2015 "Esto se podría pagar con la plata del Buen Vivir de Freddy Ehlers", en Plan V, 17 de agosto <http: / / www.planv.com.ec/historias / politicaesto-se-podria-pagar-con-la-plata-delbuen-vivir-freddy-ehlers $>$ [25 de septiembre de 2017l.

Pitarch, Pedro

2004 "The Zapatistas and the Art of Ventriloquism", en Journal of Human Rights, vol. 3, núm. 3, pp. 291-312.

Pitarch, Pedro

2007 "The Political Uses of Maya Medicine: Civil
Organizations in Chiapas and the Ventriloquist Effect”, en Social Analysis, vol. 51, núm. 2, pp. 185-206.

Radio HuANCAVILCA

2017 "Secretaría del Buen Vivir y Plan Familia suprimidas tenían planes este año”, 28 de mayo <http: / / radiohuancavilca.com.ec/noticias / 2017 / 05 / 28/ secretaria-del-buen-vivir-planfamilia-suprimidas-tenian-planes-este-ano/> [25 de septiembre de 2017].

RAHIER, JEAN M. (ED.)

2012 Black Social Movements in Latin America: From Monocultural Mestizaje to Multiculturalism, Palgrave, Nueva York.

RESISTIR ES MI DERECHO

2015 "Violencia de Estado contra mujeres indígenas que defienden sus derechos en Ecuador", en $R e$ sistires miderecho <http: / / resistiresmiderecho. org/violencia-estado-mujeres-indigenasdefienden-derechos $>$ [ 15 de diciembre de 2016].

REstrepo, EDUARDO

Y AXEL ROJAS

2010 Inflexión decolonial: fuentes, conceptos y cuestionamientos, Universidad del Cauca, Popayán.

Secretaría del Buen Vivir

2015 Buen Vivir: Sumak Kawsay. ¿Por qué? ¿Para? ¿Cómo?, Secretaría del Buen Vivir, Quito.

Torre, Carlos de la y John Antón SÁnchez

2012 "The Afro-Ecuadorian Social Movement: Between Empowerment and Cooptation", en Jean M. Rahier (ed.), Black Social Movements in Latin America: Between Empowerment and Viola, Andreu Cooptation, Palgrave, Nueva York, pp. 135-150.

2014 "Discursos pachamamistas versus políticas desarrollistas: El debate sobre el Sumak Kawsay en los Andes", en Iconos, núm. 48, pp. 55-72.

VITERI, CARLOS

2002 "Visión indígena del desarrollo en la Amazonía", en Polis, vol. 1, núm. 3, pp. 1-6.

Walsh, Catherine

2009 Interculturalidad, Estado y sociedad: luchas (de)coloniales de nuestra época, Abya Yala. Quito.

Walsh, Catherine

2015 "Affirmative Action(ing)s and Postneoliberal Movement in Latin America and Ecuador", en Cultural Dynamics, vol. 27, núm. 1, pp. 19-41.

WOLF, ERIC

1982 Europe and the People Without History, Univer-

ZAMOSC, LEÓN sity of California Press, Berkeley.

2013 "La ideología del Buen Vivir en Ecuador: ¿Una nueva ventriloquía?", ponencia presentada en la tercera conferencia de Ethnicity, Race, Indigenous People (ERIP), Oaxaca. 